LLNL-Generated Content for the

California Academy of Sciences, Morrison Planetarium Full-Dome Show:

Earthquake

A. J. Rodgers, N. A. Petersson, C. E. Morency, N.

A. Simmons, B. Sjogreen

January 24, 2012 
This document was prepared as an account of work sponsored by an agency of the United States government. Neither the United States government nor Lawrence Livermore National Security, LLC, nor any of their employees makes any warranty, expressed or implied, or assumes any legal liability or responsibility for the accuracy, completeness, or usefulness of any information, apparatus, product, or process disclosed, or represents that its use would not infringe privately owned rights. Reference herein to any specific commercial product, process, or service by trade name, trademark, manufacturer, or otherwise does not necessarily constitute or imply its endorsement, recommendation, or favoring by the United States government or Lawrence Livermore National Security, LLC. The views and opinions of authors expressed herein do not necessarily state or reflect those of the United States government or Lawrence Livermore National Security, LLC, and shall not be used for advertising or product endorsement purposes.

This work performed under the auspices of the U.S. Department of Energy by Lawrence Livermore National Laboratory under Contract DE-AC52-07NA27344. 


\title{
LLNL-Generated Content for the California Academy of Sciences, Morrison Planetarium Full-Dome Show: 'Earthquake'
}

\author{
Arthur J. Rodgers ${ }^{1}$, N. Anders Petersson ${ }^{2}$, Christina E. Morency ${ }^{1}$, Nathan A. Simmons \\ and Bjorn Sjogreen ${ }^{2}$ \\ ${ }^{1}$ Atmospheric, Earth and Energy Division, Physics and Life Sciences Directorate \\ Lawrence Livermore National Laboratory, Livermore, CA 94551 \\ ${ }^{2}$ Center for Applied Scientific Computing, Computations Directorate \\ Lawrence Livermore National Laboratory, Livermore, CA 94551
}

January 23,2012

\section{Introduction}

The California Academy of Sciences (CAS) Morrison Planetarium is producing a "fulldome" planetarium show on earthquakes and asked LLNL to produce content for the show. Specifically the show will feature numerical ground motion simulations of the $\mathrm{M}$ 7.9 1906 San Francisco and a possible future M 7.05 Hayward Fault scenario earthquake. The show will also feature concepts of plate tectonics and mantle convection using images from LLNL's G3D global seismic tomography. This document describes the data that was provided to the CAS in support of production of the "Earthquake" show.

The CAS is located in Golden Gate Park, San Francisco and hosts over 1.6 million visitors. The Morrison Planetarium, within the CAS, is the largest all digital planetarium in the world. It features a 75-foot diameter spherical section projection screen tilted at a 30-degree angle. Six projectors cover the entire field of view and give a threedimensional immersive experience. CAS shows strive to use scientifically accurate digital data in their productions. The show, entitled simply "Earthquake", will debut on 26 May 2012. We are working on graphics and animations based on the same data sets for display on LLNL powerwalls and flat-screens as well as for public release.

\section{WPP Simulations of the 1906 San Francisco Earthquake}

Ground motions for the 1906 San Francisco (SF1906) earthquake were simulated using two computer programs that cover different scales. For both simulations we used the Song2c rupture model (Aagaard et al., 2008), which describes how the earthquake evolved in time and space. This model was derived from the few available teleseismic body-wave recordings from worldwide stations that operated in 1906 as well as geodetic information on surface deformation (Song et al., 2008). The model has most of its moment release occurring north of San Francisco as well as segments where the rupture speed exceeds the local shear-wave speed (so called super-shear rupture).

On the scale of California we used the LLNL-developed WPP finite difference code (Petersson and Sjogreen, 2011) to compute the ground motions covering the entire SF1906 rupture. WPP is an open-source computer program for simulating seismic wave 
propagation in Cartesian geometries based on a second-order node-centered scheme (Petersson, 2012). This calculation used the USGS geologic/seismic (version 8.3.0, detailed + extended) model to account for known 3D structure (Aagaard et al., 2008), including viscoelastic modeling of anelastic attenuation.

The domain covered a volume with dimensions of $550 \mathrm{~km}$ along the San Andreas Fault, $200 \mathrm{~km}$ perpendicular to the fault and $40 \mathrm{~km}$ in depth. These calculations included the surface topography provided in the USGS 3D model as well as depth-dependent mesh refinement, which significantly reduced the memory requirements compared to a fixed grid size. The computational grid had a spacing of $100 \mathrm{~m}$ at the surface and a total of 1.11 Billion points. The SF 1906 rupture lasted about 90 seconds. The WPP includes approximately 117 seconds of motion after the initiation of the earthquake, outputting the norm of the horizontal velocity at the surface every 0.17 seconds. Simulations ran on the SIERRA cluster using 256 nodes (2048 CPU's) for approximately 7.5 hours. Figure 1 shows the computational domain and a snapshot of motions

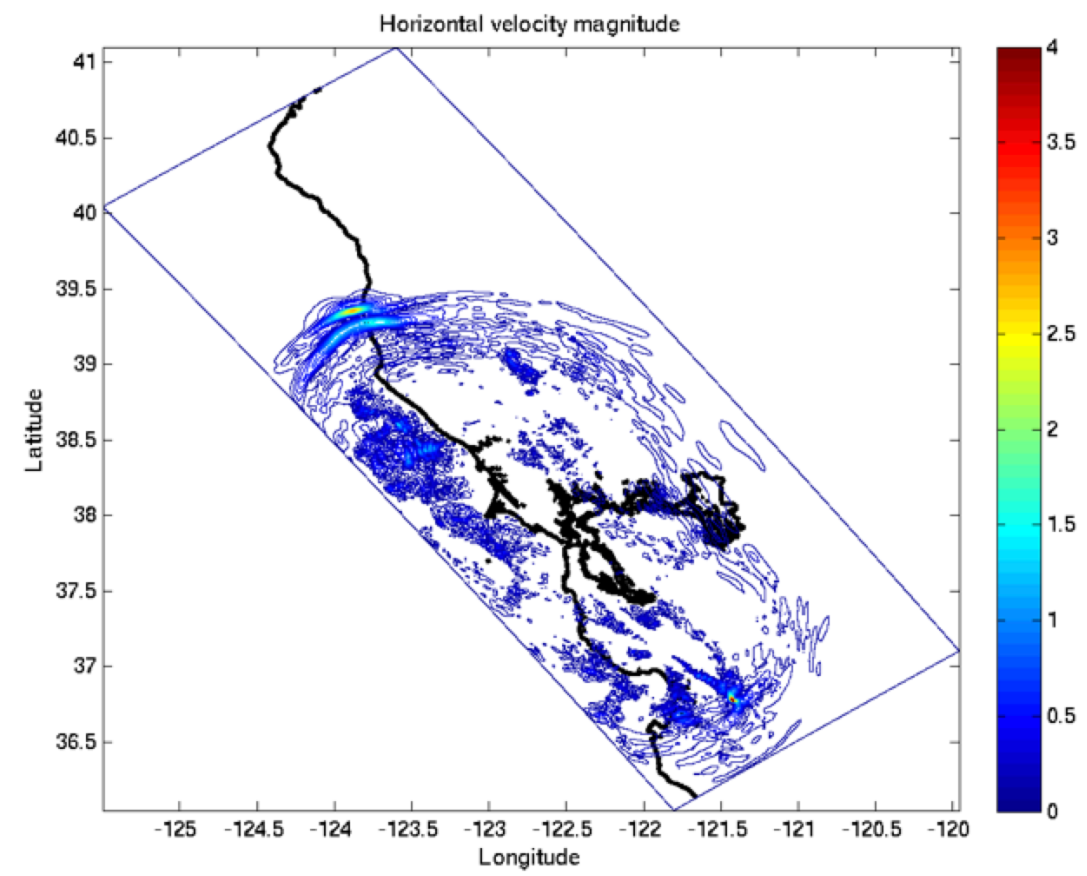

Figure 1. WPP calculation of the SF1906 earthquake using the Song2c rupture model and the USGS Bay Area geologic/seismic 3D model.

\section{SPECFEM3D_GLOBE Simulations of the 1906 San Francisco Earthquake}

In order to model the SF1906 motions on a larger scale, beyond the regions adjacent to the rupture, we used the SPECFEM3D_GLOBE spectral element method code (Tromp et al., 2008). SPECFEM3D_GLOBE is an open-source computer program for global seismic wave propagation (CIG, 2012). This program represents the spherical geometry of the earth and many important features such as the 3D variations in seismic properties, topography, bathymetry and ellipticity. We ran the code using '1-chunk' for a volume as large as a 90 -degree by 90 -degree solid angle corresponding one sixth of the earth. 
Data was generated with SPECFEM3D_GLOBE for two different calculations: one for motions at the surface and one for motions along a radial cross-section approximately parallel to the San Andreas Fault that ruptured in 1906. For both calculations we used the same Song2c rupture model (Aagaard, et al., 2008) to represent the earthquake forcing. For the material model we used the S40RTS global 3D mantle model (Ritsema et al., 2011) with the CRUST2.0 (Bassin et al., 2000) crustal model.

For surface data we ran SPECFEM3D_GLOBE with 1-chunk covering the maximum domain 90 -degree by 90 -degree solid angle and output the norm of the velocity vector at the surface. The spectral element mesh had 720 elements along each boundary at the surface with five Gauss-Lobbato Legendre points per element corresponding to an average grid point spacing of $3.5 \mathrm{~km}$ at the surface. The calculation used nearly 1 billion points. The calculation had a time step of 0.06 seconds and we output the surface motions every fifth step $(0.3$ seconds). We ran this calculation for 30 minutes after the rupture started on 75 nodes (900 CPU's) of the SIERRA cluster for approximately 8 hours of wall clock time. Figure 2 shows the domain and motions captured at about 5.5 minutes after the rupture initiated. Note that the motions are highest north of San Francisco (the epicenter) due to the higher moment release and super-shear rupture. Furthermore the wavefronts are more compact to the north due to the super-shear rupture.

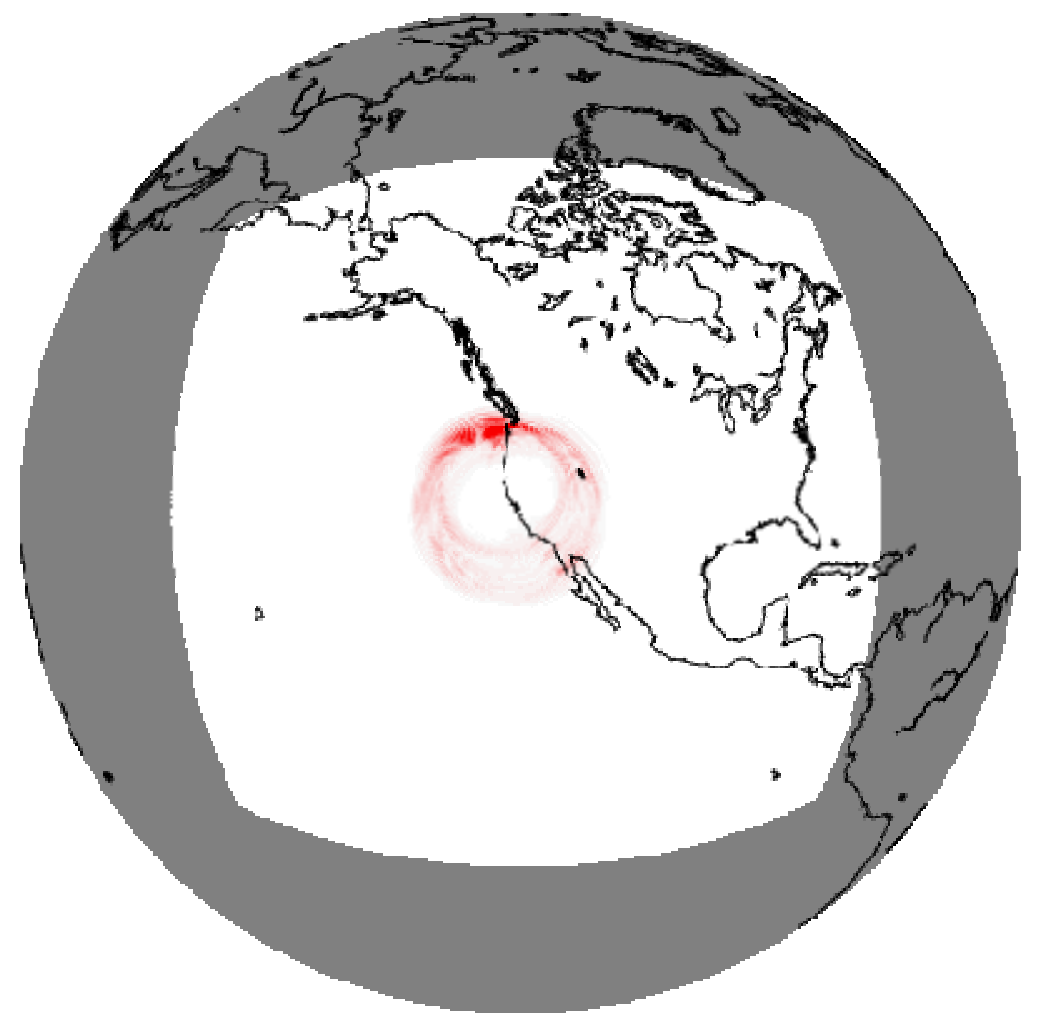

Figure 2. SPECFEM3D_GLOBE calculation of the SF1906 earthquake using the Song2c rupture model and the S40RTS mantle and CRUST2.0 crustal model showing the norm of velocity motions at the surface. 
For motions along a radial cross-section we had to output volumetric data and derive the motions on a radial cross-section in post-processing. Because of the huge amount of data written for the volume we had to limit the mesh resolution of the computational domain and run the code in several time segments using SPECFEM3D_GLOBE's restart capability. Data was provided to the CAS representing the norm of the velocity vector on a radial cross-section roughly paralleling the SF 1906 rupture. The section extends from the surface to the core-mantle boundary (2880 km depth) and spans 90 -degrees along the earth's surface. The spectral element mesh had 480 elements along each boundary at the surface. The calculation also had a time step of 0.06 seconds with volumetric outputs every fifth step. We ran the calculation for 30 minutes after the rupture started on 12 nodes (144 CPU's) of the SIERRA cluster in six segments for approximately 2.5 hours of wall clock time each.

Figure 3 shows four images of the motions along the radial cross-section at different time steps. Note that the left side of the panel corresponds to the northwest end of the section and the wave motion has higher amplitude and is more compact due to the super-shear rupture to the north of the epicenter.

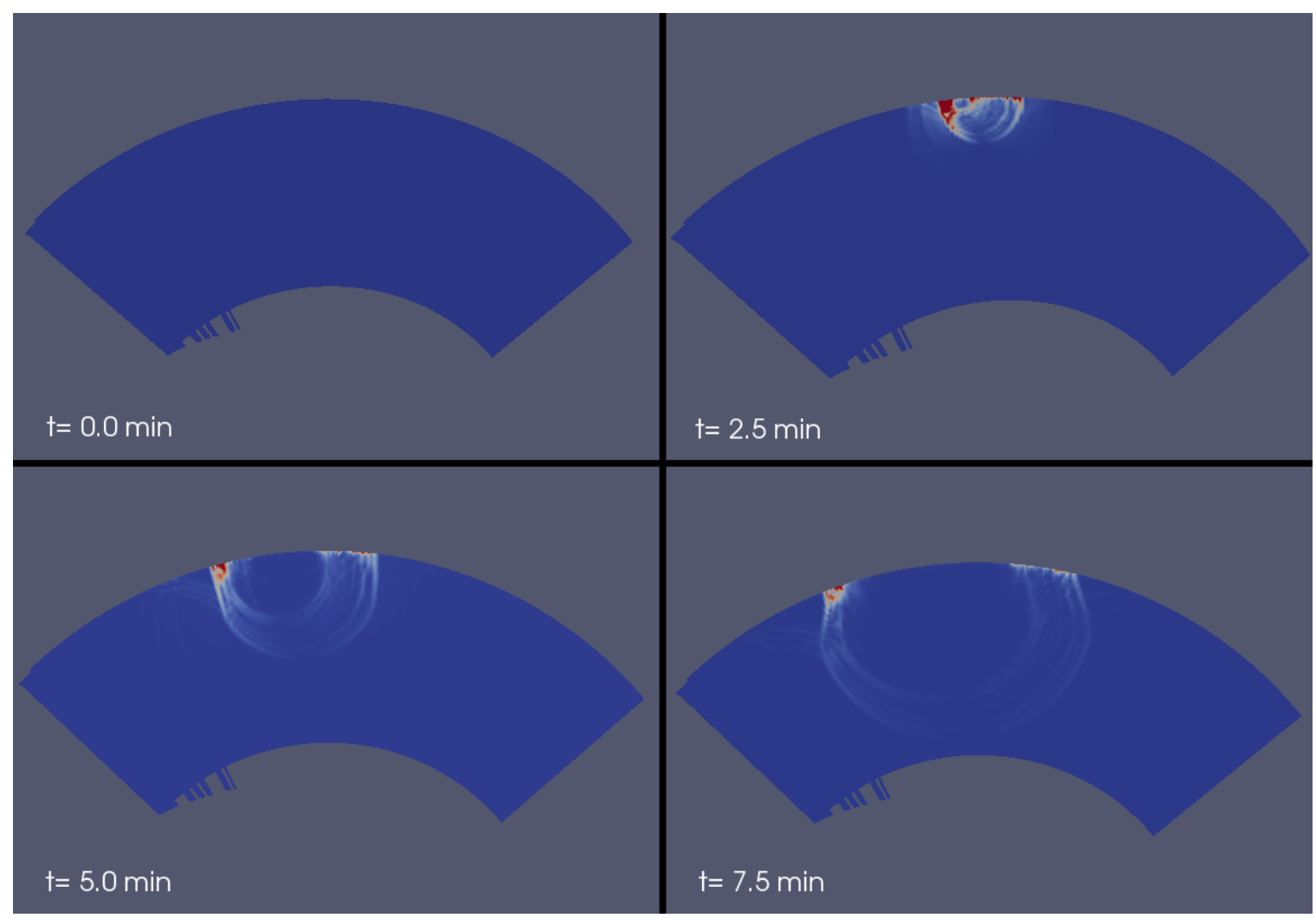

Figure 3. SPECFEM3D_GLOBE calculation of the SF1906 earthquake using the Song2c rupture model and the S40RTS mantle and CRUST2.0 crustal model showing the norm of velocity motions along a radial cross-section following the San Andreas Fault. The panels show the motions at different time steps after the rupture initiated, with the left side corresponding to the northwest end of the section. 


\section{WPP Simulations of a Hayward Fault Scenario Earthquake}

The Hayward Fault represents the highest hazard of all San Francisco Bay Area faults, with a $27 \%$ chance of producing a magnitude 6.7 or larger event in the next 30 years (Working Group on California Earthquake Probabilities (WGCEP), 2008). In order to show the potential ground shaking for a possible Hayward Fault earthquake we ran one of the scenarios considered in a recent collaborative study with the USGS and other earthquake modeling groups (Aagaard et al., 2010). This study considered 39 scenario earthquakes with moment magnitudes, $\mathrm{M}_{\mathrm{W}}$ 6.7-7.2 including segments on the Southern Hayward, Northern Hayward, Calaveras and Rodgers Creek Faults. Based on consultation with the CAS production team, we chose the HS+HN_G04_HypoO scenario from Aagaard et al. (2008), with magnitude $\mathrm{M}_{\mathrm{W}}$ 7.05.

The domain covered a volume with dimensions of $400 \mathrm{~km}$ parallel to the Hayward Fault, $240 \mathrm{~km}$ perpendicular to the fault and $40 \mathrm{~km}$ in depth. These calculations included the surface topography provided in the USGS 3D model as well as depth-dependent mesh refinement, which significantly reduced the memory requirements compared to a fixed gird size. The computational grid had a spacing of $100 \mathrm{~m}$ at the surface and a total of 0.99 Billion grid points. The Hayward scenario rupture lasted about 30 seconds. The WPP simulation includes approximately 92 seconds of motion after the initiation of the earthquake, outputting the norm of the horizontal velocity at the surface every 0.167 seconds. Simulations ran on the SIERRA cluster using 256 nodes (2048 CPU's) for approximately 4.5 hours. Figure 4 shows the computational domain and a snapshot of motions.

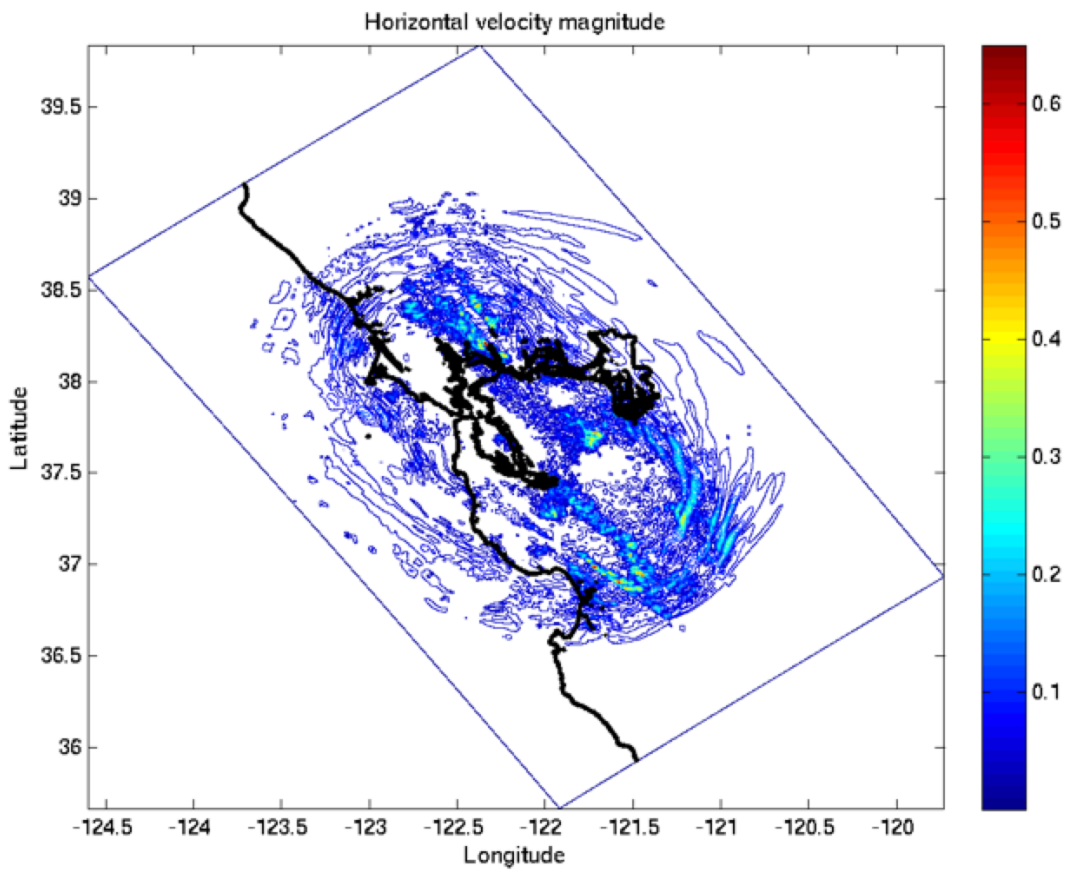

Figure 4. WPP simulation of a $\mathrm{M}_{\mathrm{W}} 7.05$ Hayward Fault scenario earthquake. 


\section{Images of Mantle Temperature from Global Seismic Tomography}

The $L L N L-G 3 D$ model is a global-scale tomographic inversion for compressional (P) seismic velocity structure in the Earth. The model is developed through inversion of millions of regional and teleseismic travel times with a technique developed at LLNL called Progressive Multi-level Tessellation Inversion (PMTI) that allows for imaging at multiple resolutions simultaneously. The imaging process involves fully $3 \mathrm{D}$ ray tracing for the most accurate prediction and modeling of the minimum time ray paths. The details of the imaging procedures can be found in Simmons et al. (2011a) and the most recent $L L N L-G 3 D$ model (used to determine temperature anomalies provided to CAS) was presented at the 2011 Fall Meeting of the American Geophysical Union (Simmons et al., 2011b).

To determine temperature variations (the product actually supplied to CAS), the $L L N L$ $G 3 D$ model was converted on the basis of the depth-dependent thermal expansivity coefficients from Karki et al. (2001) and relative heterogeneity ratios determined by joint seismic-geodynamic inversion performed by Simmons et al. (2010) (model known as GyPSuM). An example of one of the four cross sections provided to CAS is shown in Figure 5.
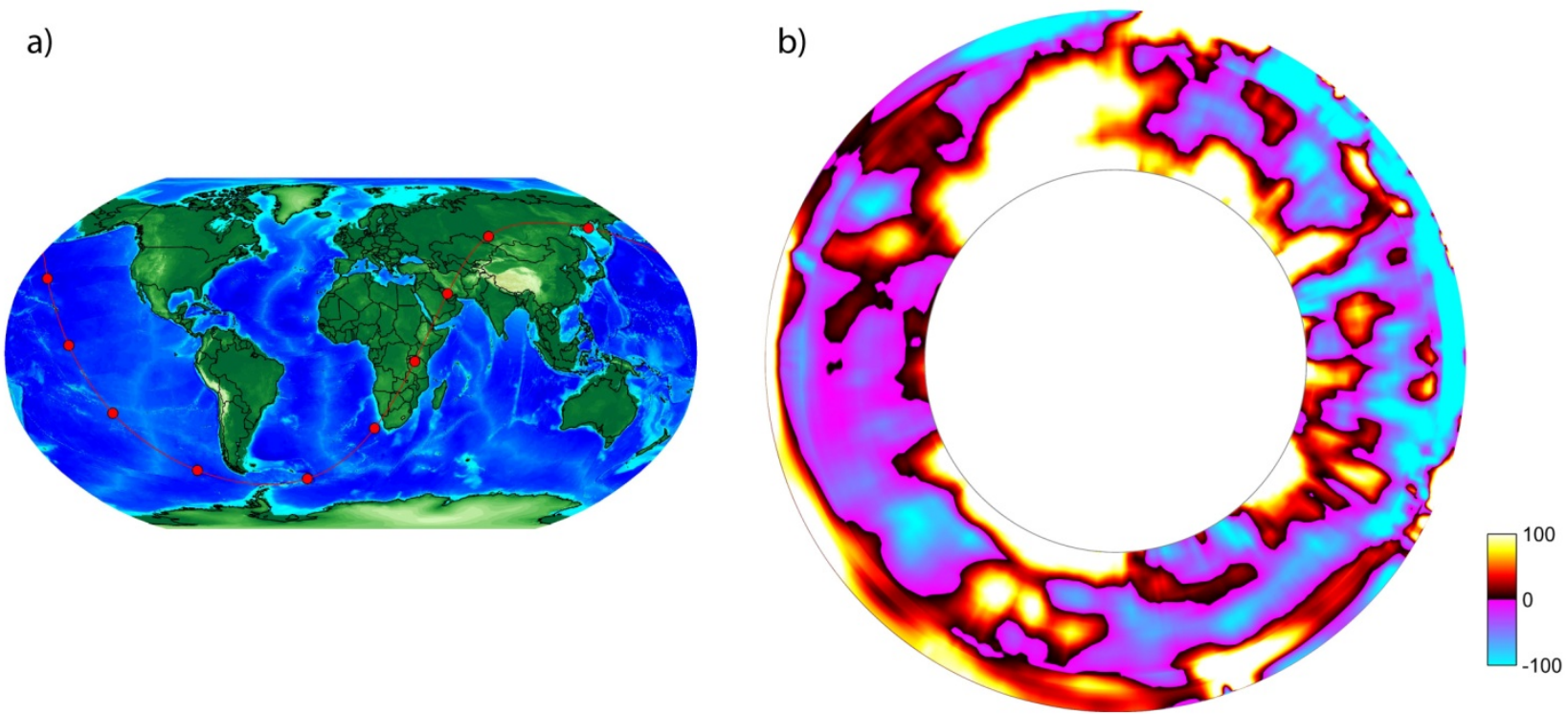

Figure 5. Temperature estimates from the LLNL-G3D P-wave velocity model. a) 360 degree great circle path through the African superplume structure. b) Estimated temperature variations (degrees Kelvin) from conversion of the LLNL-G3D model with scaling relationships described in Simmons et al. [2010].

\section{Acknowledgements}


We are grateful for the opportunity to participate in this exciting project that will be seen by a broad audience. It has been a pleasure working with the California Academy of Sciences, Morrison Planetarium visualization and production staff. In particular Ryan Wyatt, Tom Kennedy, Matt Blackwell, Mike Schmidt and Jeroen XXX provided vision, guidance and encouragement.

This effort would not be possible without access to LLNL's world-class computational facilities operated by Livermore Computing. We are grateful to Bran Carnes and Barbara Herron for access on SIERRA to complete the calculations and to Richard Hedges for assistance with $\mathrm{I} / \mathrm{O}$ issues that arose due to the enormous amount of volumetric data written by SPECFEM3D_GLOBE for visualization of waves traversing the mantle.

WPP was initially developed under funding from the Laboratory Directed Research and Development Program at LLNL and has been continued with support from the Department of Energy, Office of Science and National Nuclear Security Administration, Office of Nonproliferation Research and Engineering.

SPECFEM3D_GLOBE developed by Dimitri Komatitsch (University of Aix-Marseille) and Jeroen Tromp (Princeton University) and freely available via the Computational Infrastructure for Geodynamics (www.geodynamics.org). We are grateful for technical assistance with these calculations from Jeroen Tromp and Daniel Peter at Princeton University.

\section{References}

Aagaard, B. T., T. M. Brocher, D. Dolenc, D. Dreger, R. W. Graves, S. Harmsen, S. Hartzell, S. Larsen, K. McCandless, S. Nilsson, N. A. Petersson, A. Rodgers, B. Sjögreen, and M. L. Zoback (2008). Ground motion modeling of the 1906 San Francisco earthquake II: Ground motion estimates for the 1906 earthquake and scenario events, Bull. Seismol. Soc. Am. 98, no. 2, 1012-1046, doi 10.1785/0120060410.

Aagaard, B. T., R. W. Graves, A. Rodgers. T. M. Brocher, R. W. Simpson, D. Dreger, N. Anders Petersson, S. C. Larsen, S. Ma, and R. C. Jachens (2010). Ground-motion modeling of Hawyard fault scenario earthquakes, Part II: Simulation of long-period and broadband ground motions Bull. Seism. Soc. Am., 100, 2945-2977.

Bassin, C., Laske, G. and Masters, G. (2000). The Current Limits of Resolution for Surface Wave Tomography in North America, EOS Trans AGU, 81, F897.

Computational Infrastructure for Geodynamics, CIG (2012). http://www.geodynamics.org/cig/software/specfem3d-globe, website accessed January $21,2012$. 
Karki, B. B., R. M. Wentzcovitch, S. de Gironcoli, and S. Baroni (2001), First principles thermoelasticity of $\mathrm{MgSiO} 3$ - perovskite: Consequences for inferred properties of the lower mantle, Geophys. Res. Lett., 28(14), 2699-2702.

Petersson, N. A. and B. Sjogreen (2011). User's guide to WPP version 2.1.5, LLNL technical report, LLNL-SM-487431.

Petersson, N. A. (2012). https://computation.llnl.gov/casc/serpentine/software.html, website accessed January 21, 2012.

Ritsema, J., H. J. van Heijst, A. Deuss, and J. H. Woodhouse (2011). S40RTS: a degree40 shear velocity model for the mantle from new Rayleigh wave dispersion, teleseismic traveltimes, and normal-mode splitting function measurements, Geophys. J. Int., 184, $1223-1236$.

Simmons, N. A., S. C. Myers, and G. Johannesson (2011). Global-scale P-wave tomography optimized for prediction of teleseismic and regional travel times for Middle East events: 2. Tomographic inversion, J. Geophys. Res., 116, B04305.

Simmons, N.A., A.M. Forte, L. Boschi, and S.P. Grand (2010). GyPSuM: A joint tomographic model of mantle density and seismic wave speeds J. Geophys. Res. Vol. 115, B12310, doi:10.1029/2010JB007631.

Simmons, N.A, S.C. Myers, and G. Johannesson (2011a). Global-scale P-wave tomography optimized for prediction of teleseismic and regional travel times for Middle East events: 2. Tomographic inversion. J., Geophys. Res., 116(B04304), doi:10.1029/2010JB007967.

Simmons, N.A, S.C. Myers, G. Johannesson, and E. Matzel (2011b). The $L L N L-G 3 D$ global P-wave velocity model and the significance of the BayesLoc multiple-event location procedure, Abstract S43B-2237 presented at 2011 Fall Meeting, AGU, San Francisco, California, 5-9 December.

Song, S.-G., G. Beroza and P. Seagall (2008). A Unified Source Model for the 1906 San Francisco Earthquake, Bull. Seismol. Soc. Am. 98, 823-831, doi: 10.1785/0120060402.

Tromp, J., D. Komatitsch and Q. Liu (2008). Spectral-element and adjoint methods in seismology, Comm. Comp. Phys., 3, 1-32.

Working Group on California Earthquake Probabilities (2008). The uniformCalifornia earthquake rupture forecast, version 2 (UCERF 2), U.S. Geol. Surv. Open-File Report 2007-1437, http://pubs.usgs.gov/of/2007/1437/ (last accessed January 21, 2012). 